\title{
Weed Control in Sweet Corn ${ }^{1}$
}

William M. Stall ${ }^{2}$

Weeds reduce yield and quality of sweet corn by direct competition for light, water and nutrients in the soil. Weeds may also harbor insect and disease pests that attack corn. Estimated average annual losses due to weeds in sweet corn in the United States, 1975 to 1979 were 1,460,000 cwt of fresh market sweet corn worth $\$ 13,165,000$ and $185,000 \mathrm{cwt}$ of sweet corn for processing with a value of $\$ 9,155,000$.

Historically, the major reason for corn being grown in rows was weed control. Row width was dictated by the widths that horses needed to pass between the rows pulling a cultivator.

Today, in-row spacing has been refined for the greatest yield and quality. Between row spacings are still variable due to culture and tire widths.

Mechanical cultivation of sweet corn is still widespread. The initiation of the use of selective herbicides some forty years ago in corn has decreased the number of cultivations needed per season. This has substantially lowered the fossil fuel energy used in sweet corn production. Many sweet corn fields now receive one cultivation or no cultivations at all. Much of the cultivation used is to reduce surface crusting or to control weeds resistant or not controlled by the herbicide combinations selected. There is at the present time a wide selection of herbicides to control most weeds in sweet corn.
The wide selection is, however, being reduced due to nonreregistration of older compounds, and suspensions due to leaching into the groundwater. Alachlor (Lasso) has been restricted from use in Florida due to confirmed groundwater contamination. Atrazine also is under suspicion.

Herbicide treatments are primarily categorized on the basis of the time of application, preplanting, pre-emergence, and post emergence. Preplanting treatments are applied before the sweet corn is planted and either applied as a surface treatment or incorporated into the soil. Pre-emergence application is after the sweet corn is seeded but before emergence of the sweet corn or weeds. Preplant and pre-emergence herbicides, properly selected and applied, prevent weed competition during emergence and early seedling growth. Post emergence applications take place after the emergence of both the sweet corn and weeds. These are most effective when weeds are small.

Many post-emergence labels will state specific ages or growth stages of the sweet corn and weeds to be sprayed. These stages may be the spike stage, 5-leaf stage, or when plants are 30 inches tall. If the label specifies directing a spray to the bottom or side of a plant, care must be taken to follow these directions or severe damage may occur.

Herbicide performance depends on weather, irrigation method, soil type, as well as proper selection for weed

1. This document is HS197, one of a series of the Horticultural Sciences Department, Florida Cooperative Extension Service, Institute of Food and Agricultural Sciences, University of Florida. Revised April 2009. Please visit the EDIS Web site at http://edis.ifas.ufl.edu.

2. William M. Stall, professor, Horticultural Sciences Department, Cooperative Extension Service, Institute of Food and Agricultural Sciences, University of Florida, Gainesville, 32611.

The use of trade names in this publication is solely for the purpose of providing specific information. It is not a guarantee or warranty of the products named, and does not signify that they are approved to the exclusion of others of suitable composition.

The Institute of Food and Agricultural Sciences (IFAS) is an Equal Opportunity Institution authorized to provide research, educational information and other services

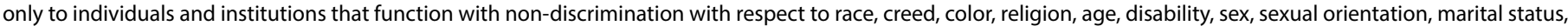

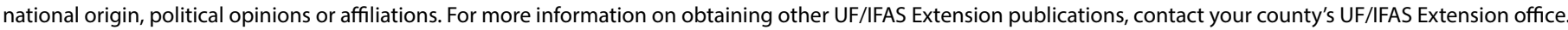
U.S. Department of Agriculture, UF/IFAS Extension Service, University of Florida, IFAS, Florida A \& M University Cooperative Extension Program, and Boards of County Commissioners Cooperating. Nick T. Place, dean for UF/IFAS Extension. 
species to be controlled and accurate application and timing. Obtain consistent results by reading the herbicide label and other information about proper application and timing of each herbicide.

Recent research has shown that there is a difference in tolerance to herbicides especially among the new sh2 (super sweet) cultivars. Because cultivars may have different tolerances, we suggest that growers test herbicides on a trial basis when changing cultivars.

Several sulfonyl urea herbicides labeled on field corn (i.e. Accent and Beacon) will cause damage on a large number of sweet corn cultivars, and are not recommended for use. Use only labeled herbicides and those herbicides in the proper formulations. Check the labels of each herbicide for tank mix recommendations. To avoid confusion between formulations, suggested rates listed in Table 1 are stated in pounds active ingredient per acre (lb. ai. /acre).

Several listed herbicides are also labeled for tank-mix combinations. Read the label of each formulation for tank-mix specifications and compatibilities. There are also several Pre-mix herbicides labeled for sweet corn. A few of them are listed in Table 2.

There are more Pre-mix herbicides that are labeled. Read the labels for specific rates recommended. 


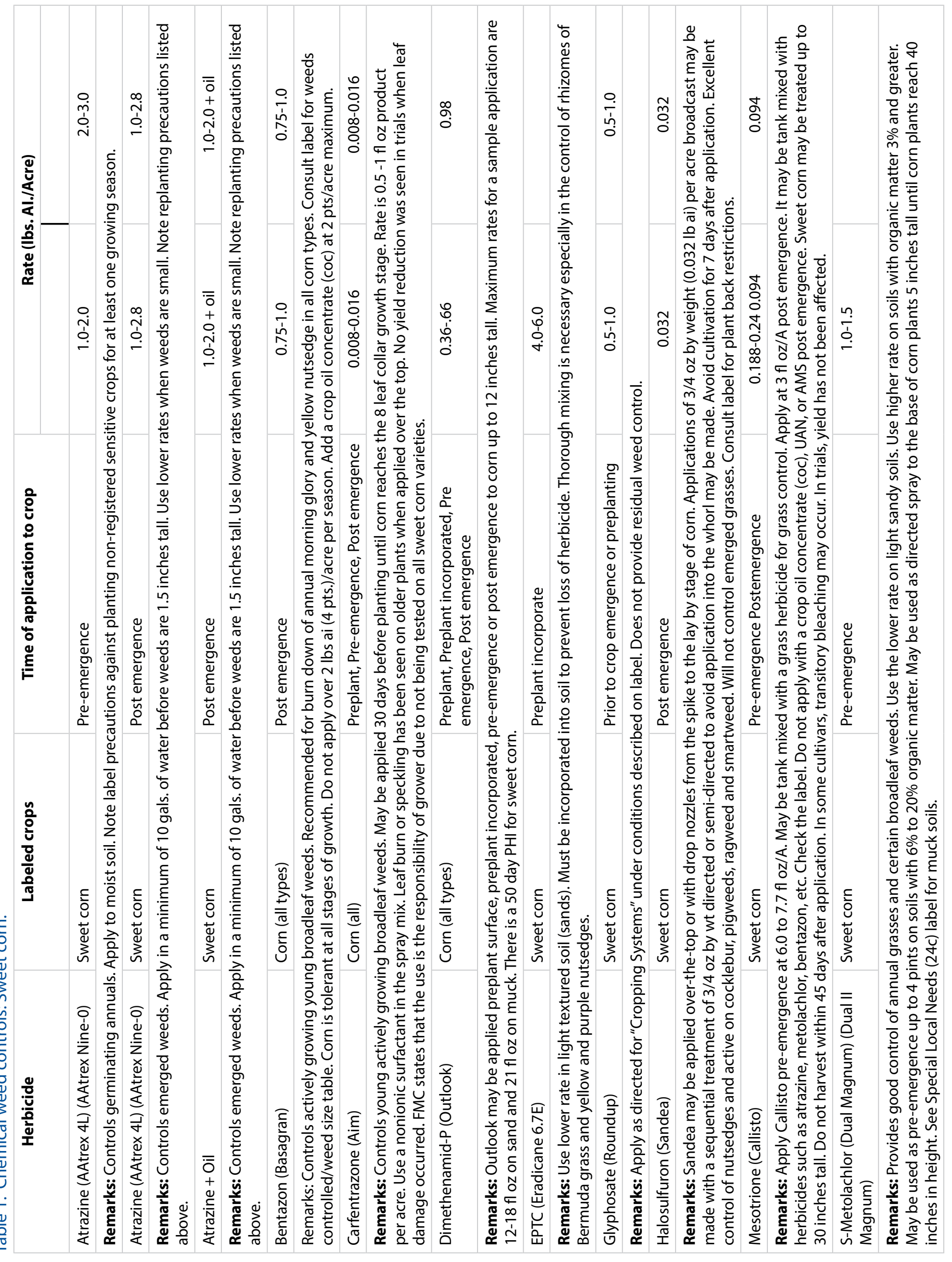




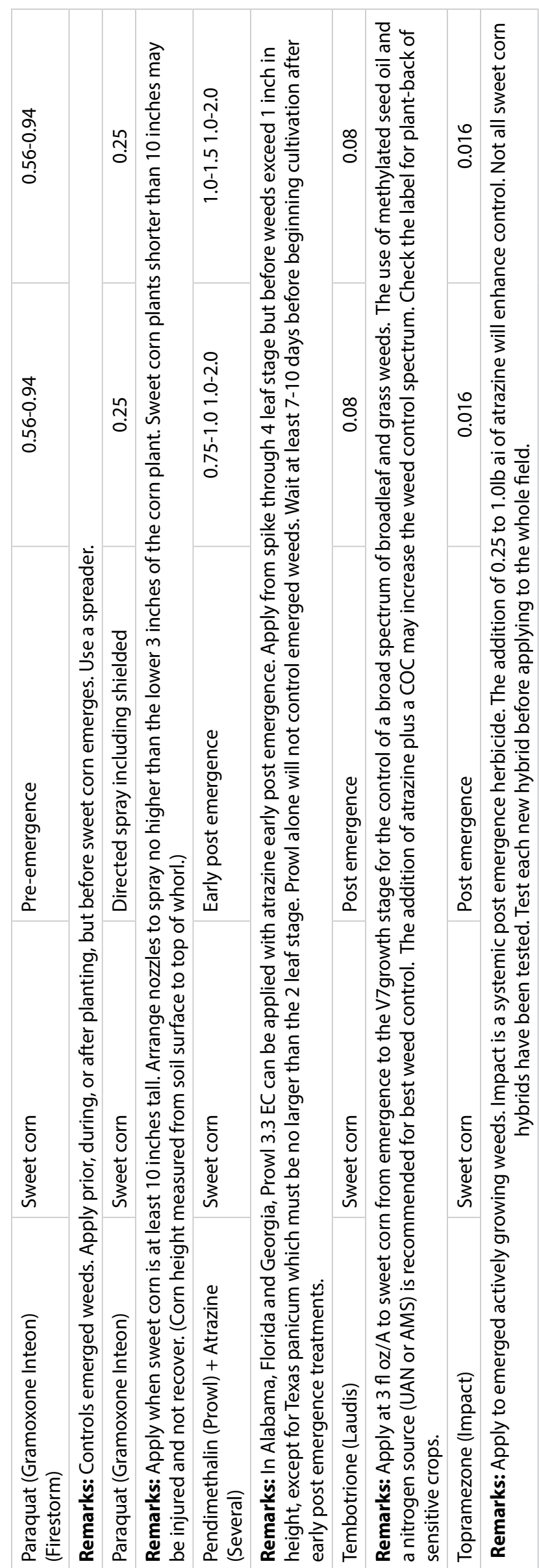


Table 2.

\begin{tabular}{|l|l|}
\hline Trade Name & Common Names \\
\hline Bicep & atrazine + metolachlor \\
\hline Laddok & atrazine + bentazon \\
\hline G-max & atrazine+ dimethenamid \\
\hline
\end{tabular}

